Rio de Janeiro. Ano 11. Volume 18. Número 3. Setembro a Dezembro de 2017

Periódico Quadrimestral da Pós-Graduação Stricto Sensu em Direito Processual da UERJ

Patrono: José Carlos Barbosa Moreira. ISSN 1982-7636. pp. 122-145

www.redp.uerj.br

\title{
AS POSSIBILIDADES DE SOLUÇÃO CONSENSUAL DE CONFLITOS JUDICIAIS COM A ADMINISTRAÇÃO PÚBLICA ${ }^{1}{ }^{2}$
}

\section{THE POSSIBILITIES OF CONSENSUAL SOLUTION OF JUDICIAL CONFLICTS WITH THE PUBLIC ADMINISTRATION}

Gabriel Perlingeiro Advogado no Rio de Janeiro. Bacharel em Direito pela UFF. g.perlingeiro@terra.com.br

\begin{abstract}
RESUMO: O texto procura fixar dogmaticamente os limites da possibilidade de a Administração Pública empreender soluções consensuais de conflitos no bojo do processo judicial. Inspira-se na falta de uma compreensão clara acerca da zona fronteiriça entre as relações jurídicas de direito público e de direito privado envolvendo as autoridades públicas e das expressões "direito indisponível" (ou "interesse indisponível") e "interesse público" evidenciada em uma inexplicável assimetria entre o que a Administração pode fazer fora e dentro do processo. Para tanto, a partir de uma pesquisa primordialmente doutrinária, revisita a relação entre interesse público e indisponibilidade, demonstrando, ao fim, que a possibilidade de a Fazenda realizar transação ou praticar condutas determinantes no processo judicial não deve ser aprioristicamente rechaçada, nem mesmo nas relações de direito público. Segundo o autor, são três os possíveis cenários de solução consensual por parte da Fazenda Pública no bojo do processo judicial: diante de relações de direito privado, diante de relações de direito público no que toca ao exercício do poder vinculado e diante de relações de direito público no que toca ao exercício do poder discricionário.
\end{abstract}

PALAVRAS-CHAVE: acesso à justiça; interesse público; autocomposição; Fazenda Pública; poder discricionário.

\footnotetext{
${ }^{1}$ Artigo recebido em 09/10/2017 e aprovado em 29/11/2017.

${ }^{2}$ Adaptação do Trabalho de Conclusão de Curso - TCC -, apresentado sob a orientação do Prof. Dr. Marcelo Pereira de Almeida, no dia 19 julho de 2017, na Faculdade de Direito da Universidade Federal Fluminense UFF (Niterói/RJ).
} 
ABSTRACT: This text endeavors to define the theoretical limits of the capacities of the public administrative authorities to reach consensual solutions to disputes within the framework of judicial review. It is motivated by the lack of a clear understanding in Brazilian law of the border area between the legal relations of public and private law involving the public authorities, and the expressions "inalienable right" (or "inalienable interest") and "public interest" as shown by the inexplicable asymmetry between what the public administrative authorities can do within a judicial proceeding and outside one. Based on a comparative study of common law versus civil law legal systems and an examination of the treatment of the subject in Brazilian statutes, case law and legal studies, this article reviews the relationship between the public interest and inalienability, demonstrating, in conclusion, that the possibility of the administrative authorities to enter into settlements or follow similar practices should not be rejected a priori, even in cases of public law. According to the author, there are three possible scenarios for a consensual solution on the part of the public administrative authorities in the context of the judicial process: before private law relations, before public law relations in relation to the exercise of the binding power and before public law relations in relation to the exercise of discretion.

KEYWORDS: fair trial; judicial review; public interest; consensual dispute resolution; administrative authority, discretionary powers of administrative authorities.

SUMÁRIO: 1. Introdução - 2. Soluções consensuais de conflitos judiciais - 3. Relações de direito privado e direito público -4 . Interesse público -5 . Soluções consensuais pela Fazenda Pública no direito privado - 6. Soluções consensuais pela Fazenda Pública no direito público - 7. Conclusão - Referências

\section{Introdução}

A falta de uma compreensão clara acerca da relação entre direito privado, direito público, interesse público e indisponibilidade, expressada pela doutrina e jurisprudência, evidencia situações de incoerência no direito pátrio. São múltiplas as decisões judiciais que 
Revista Eletrônica de Direito Processual - REDP.

Rio de Janeiro. Ano 11. Volume 18. Número 3. Setembro a Dezembro de 2017

Periódico Quadrimestral da Pós-Graduação Stricto Sensu em Direito Processual da UERJ

Patrono: José Carlos Barbosa Moreira. ISSN 1982-7636. pp. 122-145

www.redp.uerj.br

negam à Fazenda Pública a capacidade de realizar transação judicial, de desistir ou de reconhecer o pedido adverso ao argumento de se estar diante de matéria indisponível, pois atinente ao interesse público ${ }^{3}$. Observa-se que a rejeição do Judiciário à autocomposição subsiste ainda que, fora do processo, seja viável e, não raro, obrigatória a sua realização pelo Poder Público, revelando-se uma inexplicável assimetria entre o que a Administração pode fazer fora e dentro do processo judicial.

Muitas dúvidas orbitam esse tema, sobretudo quando a Administração capitaneia uma relação de direito público. Se, por um lado, argumenta-se que os meios autocompositivos não são adequados às decisões administrativas, pois estas envolvem valores inegociáveis, por outro, advoga-se pelo seu cabimento, diante dos benefícios que o consensualismo pode representar para as relações entre os cidadãos e o Estado ${ }^{4}$.

Ainda que haja previsão em leis brasileiras (e.g. Lei $n^{\circ} 9.469$, de 10 de julho de $1997^{5}$ e Lei ${ }^{\circ} 13.140$, de 16 de junho de $2015^{6}$ ), algumas leis latino-americanas, como as do Peru, ${ }^{7}$ Guatemala, ${ }^{8}$ Argentina, Colômbia, México, Nicarágua e Panamá, ${ }^{9}$ e assentado no Código Modelo de Processos Administrativos - Judicial e Extrajudicial - para Ibero-

\footnotetext{
${ }^{3}$ BRASIL. Supremo Tribunal de Justiça. AgRg no REsp 634.971 / DF. Brasília, 05 de outubro de 2004 ; BRASIL. Supremo Tribunal de Justiça. REsp 1198424 PR 2010/0108482-2. Brasília, 12 de abril de 2012. Ver PERLINGEIRO, Ricardo. Desafios contemporâneos da justiça administrativa na América Latina. Revista de Investigações Constitucionais, Curitiba, v. 4, n.1, p. 188, jan./abr. 2017.

${ }^{4}$ KINCHIN, Niamh H. Mediation and Administrative Merits Review: An Impossible Goal? Australasian Dispute Resolution Journal, Riverwood, v. 18, n.4, p. 233, 2007.

${ }^{5}$ Destacam-se os arts. $1^{\circ}$ e $4^{\circ}$-A da Lei no 9.469 , de 10 de julho de 1997, que cuida sobre transação judicial pela Fazenda Pública Federal.

${ }^{6}$ Faz-se o registro ainda do art. 35 da Lei $\mathrm{n}^{\circ} 13.140$, de 16 de junho de 2015 , que também se restringe à Administração Federal.

${ }^{7}$ Ley que regula el proceso contencioso administrativo do Peru (Lei no 27.584 , de 29 de Agosto de 2008): "Art. 43. Transacción o conciliación. En cualquier momento del proceso, las partes podrán transigir o conciliar sobre pretensiones que contengan derechos disponibles. Si el acuerdo homologado o aprobado es total, producirá la conclusión del proceso. De ser parcial, el proceso continuará sobre los aspectos no comprendidos. Para proponer o acceder a la fórmula de composición, la entidad deberá analizar objetivamente la expectativa de éxito de su posición jurídica en el processo."

${ }^{8}$ Ley de lo contencioso administrativo da Guatemala (Decreto $\mathrm{n}^{\circ}$ 119/96, de 21 de novembro de 1996): "Art. 36. Excepciones previas. Los emplazados pueden interponer dentro del quinto día del emplazamiento, las siguientes excepciones previas: [...] j) Transacción."

${ }^{9}$ Na América Latina, também é possível apontar os seguintes dispositivos relativos à matéria: Art. 29, 67, 144, 258, 259, 282, 289 e 393 do Código Contencioso Administrativo y Tributario de la Ciudad de Buenos Aires (Lei n ${ }^{\circ}$ 189, de 13 de maio de 1999); Art. 104, 161, 164, 176, 180, 192, 195, 243, 251, 303 do Código de Procedimiento Administrativo y de lo Contencioso Administrativo da Colômbia (Lei n ${ }^{\circ}$ 1.437, de 18 de janeiro de 2011); Art. 59, 66, 67, 69, 70, 72, 73, 117 do Código Procesal Contencioso-Administrativo da Costa Rica (Lei $\mathrm{n}^{\circ}$ 8.508, de 28 de abril de 2006); Art. 57 da Ley Federal de Procedimiento Administrativo do México (Lei de 4 de agosto de 1994); Art. 55, 56, 97, 98 da Ley de regulación de la jurisdicción de lo contencioso-administrativo da Nicarágua (Lei ${ }^{\circ}$ 350, de 18 de maio de 2000); Art. 110, 153, 201 do Estatuto Orgánico de la Procuraduría de la Administración, regula el Procedimiento Administrativo General y dicta disposiciones especiales do Panamá (Lei no 38 , de 31 de julho de 2000).
} 
Revista Eletrônica de Direito Processual - REDP.

Rio de Janeiro. Ano 11. Volume 18. Número 3. Setembro a Dezembro de 2017

Periódico Quadrimestral da Pós-Graduação Stricto Sensu em Direito Processual da UERJ

Patrono: José Carlos Barbosa Moreira. ISSN 1982-7636. pp. 122-145

www.redp.uerj.br

América $^{10}$ e no Euro-American Model Code of Administrative Jurisdiction ${ }^{11}$, permitindo o uso de meios consensuais por parte da Fazenda Pública dentro do processo, nenhum deles deixa satisfatoriamente claras as situações em que se aplicam.

Nesse cenário, este estudo, a partir de uma pesquisa primordialmente doutrinária, procura fixar dogmaticamente os limites da possibilidade de a Administração Pública empreender soluções consensuais de conflitos no bojo do processo judicial. O texto analisa a questão sob duas óticas: das relações de direito privado e das relações de direito público. Ressalta-se que este ensaio não se prende aos limites do Direito posto, oferecendo uma proposta dogmática da análise da matéria.

Para tanto, em primeiro lugar, o autor examina a aplicação dos mecanismos de autocomposição dentro do processo judicial. Em segundo lugar, delimita a fronteira entre o direito privado e o direito público. Em seguida, revisita a relação entre o interesse público e indisponibilidade. Por fim, assenta as balizas do emprego de soluções consensuais por parte da Fazenda Pública no curso do processo judicial, quando participa, respectivamente, de relações de direito privado e de direito público.

\footnotetext{
${ }^{10}$ Art. 71-73 do Código Modelo de Processos Administrativos - Judicial e Extrajudicial - para Ibero-América (GRINOVER et al. Código Modelo de Processos Administrativos - Judicial e Extrajudicial - para IberoAmérica. Revista Eletrônica de Direito Processual, Rio de Janeiro, v. X, p. 360-383, 2012): Art. 71. Alternatividade. Ressalvados os casos de nulidade dos atos administrativos, as partes poderão recorrer a outros meios adequados de solução de controvérsia, tais como arbitragem, conciliação, mediação, transação e composição amigável. Art. 72. Princípios. O uso de meios alternativos de solução de controvérsias com a Administração estará sujeito aos seguintes princípios: I - Legalidade. A arbitragem e os acordos com a Administração destinados a prevenir ou extinguir um litígio devem estar respaldados no princípio da legalidade de maneira a garantir a não afetação do patrimônio público ou sua conformidade com o ordenamento jurídico; II - Isonomia. Os acordos que envolvam normas administrativas ou atuações de alcance geral devem atingir todos aqueles que se encontrarem na mesma situação fática, ainda que desses acordos não tenham participado; III - Transigibilidade. Somente se poderá fazer uso de outros mecanismos de solução de conflitos quando suas formas e modalidades de solução forem transigíveis. Art. 73. Cabimento. Também procederão outros meios adequados de solução de controvérsias, quando, sendo o conflito de caráter particular, decorrer de atos administrativos.

${ }_{11}$ Art. 35-37 do Euro-American Model Code of Administrative Jurisdiction (PERLINGEIRO, Ricardo; SOMMERMANN, Karl-Peter. Euro-American Model Code of Administrative Jurisdiction: English, French, German, Italian, Portuguese and Spanish Versions. Niterói: Editora da UFF, 2014): Art. 35. Princípio. O tribunal, de ofício ou por solicitação da parte, poderá submeter à consideração das partes a possibilidade de alcançar um acordo que ponha fim à controvérsia, na medida em que possam dispor do objeto da conciliação. Art. 36. Procedimento. Uma vez formulada a demanda e sempre que não seja manifesta- mente inadmissível, o presidente do tribunal, ou o juiz por ele designado, pode, respeitando o caráter contraditório do processo, realizar qualquer diligência que permita a conclusão de um acordo entre as partes. Art. 37. Homologação do acordo e vias de recurso. 1) Sempre que o acordado não for contrário ao ordenamento jurídico nem manifestamente lesivo do interesse público ou de terceiros, o tribunal homologará o acordo e proferirá decisão, declarando concluído o processo sobre os pontos do acordo. 2) A decisão de homologação citada no parágrafo precedente tem a mesma autoridade que as sentenças do tribunal. Os terceiros lesionados pelo acordo que não forem partes no procedimento podem recorrer da decisão de homologação dentro de um prazo de dois meses, ante o mesmo tribunal.
} 
Rio de Janeiro. Ano 11. Volume 18. Número 3. Setembro a Dezembro de 2017

Periódico Quadrimestral da Pós-Graduação Stricto Sensu em Direito Processual da UERJ

Patrono: José Carlos Barbosa Moreira. ISSN 1982-7636. pp. 122-145

www.redp.uerj.br

\section{Soluções consensuais de conflitos judiciais}

As soluções consensuais ocorrem na medida em que uma das partes consente espontaneamente em sacrificar interesse próprio em favor do interesse adverso, com vistas a dar fim à contenda. Ela pode acontecer antes ou após a instauração de um conflito judicial $^{12}$. Trata-se de forma alternativa de resolução de conflitos à jurisdição (Alternative Dispute Resolution ${ }^{13}$ ).

No curso do processo judicial, a autocomposição pode se dar de três maneiras: a) transação, na qual ocorrem concessões mútuas (art. 487, III, $b$, CPC); b) renúncia, a partir da qual o autor abdica da sua pretensão (art. 487, III, $c$, CPC); e c) reconhecimento da procedência do pedido, quando o réu se submete voluntariamente ao pleito autoral (art. 487, III, $a, \mathrm{CPC})^{14}$. Ademais, ela pode ocorrer de forma espontânea, por iniciativa das partes, ou de forma estimulada, como resultado de um procedimento de mediação ou conciliação ${ }^{15}$.

Os meios autocompositivos têm sido cada vez mais fomentados pelo legislador brasileiro. Essa tendência é corroborada pelo novo Código de Processo Civil: a) assenta a tentativa de solução consensual entre as suas normas fundamentais (art. $3^{\circ}, \S \S 2^{\circ}$ e $3^{\circ}$, CPC); b) estabelece a tentativa de autocomposição como etapa obrigatória do rito processual, precedendo o oferecimento da contestação pelo réu (art. 334 e 695, CPC); c) regulamenta o procedimento de mediação e conciliação (art. 165-175, CPC); d) permite a celebração de acordos judiciais, ainda que relativos a matéria estranha ao objeto do processo, bem como acordos que envolvam terceiros alheios à relação processual (art. 515, $\S 2^{\circ}$, CPC); e) autoriza a promoção de negócios jurídicos processuais atípicos (art. 190, (PC) ${ }^{16}$.

\footnotetext{
${ }^{12}$ DIDIER JÚNIOR, Fredie. Curso de Direito Processual Civil. v.1, 17.ed. rev. atual. e ampl. Salvador: Editora Jus Podium, 2015. p. 165.

${ }^{13}$ GELLHORN, Ernest; LEVIN, Ronald M. Administrative Law and Process in a Nutshell. 5. ed. St. Paul: Thomson/West, 2006. p. 169.

${ }^{14} \mathrm{O}$ reconhecimento da procedência do pedido pode se realizar de forma expressa ou tácita. Nesta última hipótese, incluem-se a figura da revelia (art. 344, CPC) e a da ausência de impugnação específica dos fatos alegados na inicial (art. 341, CPC).

${ }^{15}$ MARINONI, Luiz Guilherme; ARENHART, Sérgio Cruz; MITIDIERO, Daniel. Curso de Processo Civil: Teoria do Processo Civil. v. 1. São Paulo: Editora Revista dos Tribunais, 2015. p. 180.

${ }^{16}$ DIDIER JÚNIOR, Fredie. Curso de Direito Processual Civil. v.1, 17.ed. rev. atual. e ampl. Salvador: Editora Jus Podium, 2015. p. 166.
} 
Nicola Picardi sustenta que o recurso à autocomposição pressupõe três elementos: a observância da ordem pública e do bom costume, o consenso das partes e a disponibilidade do direito sacrificado ${ }^{17}$.

O primeiro requisito compreende o respeito às normas imperativas e aos princípios basilares do ordenamento. Dessa forma, seria inviável, por exemplo, que a Administração Pública participasse de procedimento conciliatório confidencial, eis que sua atuação deve sempre ser pautada pelo princípio da publicidade (art. 37, CRFB).

A segunda condição decorre do princípio do amplo acesso à jurisdição (art. $5^{\circ}$, XXXV, CRFB). Uma vez instaurado o processo, as partes não podem ser forçadas a aderir a acordo. A decisão de ultimar o processo, dispensando-se o pronunciamento judicial sobre a matéria, pertence tão somente aos sujeitos da relação processual.

A respeito do último pressuposto, o autor afirma:

I procedimenti alternativi presuppongono la disponibilità del diritto. Como è noto, funzione della giurisdizione civile è la tutela di posizioni giuridiche sostanziali, posizioni che possono consistere in diritti disponibili, ovvero in diritti indisponibili. In questa seconda ipotesi, è sbarrata la via della conciliazione. [...] Nella ipotesi di diritti disponibili si aprono, invece, diverse possibilità. Le parti possono rinunciare ai loro diritti oppure possono stipulare una transazione, con la quale, mediante reciproche concessioni, compongono o prevengono la controversia fra loro insorta ${ }^{18}$.

Assim, nota-se que a possiblidade de o sujeito renunciar ao seu direito se reflete na viabilidade de soluções consensuais. Se o interesse for indisponível, seu titular não poderá abrir mão, sequer parcialmente, do direito que lhe assiste, obstaculizando, não apenas a renúncia total (reconhecimento do pedido adverso e renúncia stricto sensu), mas também a renúncia parcial (transação) da posição que defende. A regra encerra corolário lógico da proteção conferida pelo ordenamento jurídico a direitos cuja importância afirma-se ser superior à autonomia das partes.

\footnotetext{
${ }^{17}$ PICARDI, Nicola. Manuale del Processo Civile. 2.ed. Milano: Giuffrè Editore, 2010. p. 657.

${ }^{18}$ Ibid., p. 657. Tradução livre: Os procedimentos alternativos pressupõem a disponibilidade do direito. Como é sabido, a jurisdição civil tem como função a tutela de posições jurídicas substanciais, posições estas que podem consistir em direitos disponíveis ou direitos indisponíveis. Nessa segunda hipótese, está vedada a via da conciliação. [...] No caso de direitos disponíveis, de outro lado, deparam-se com várias possibilidades. As partes podem renunciar aos seus direitos ou celebrar transações, com as quais, mediante concessões mútuas, compõem ou previnem controvérsia entre eles surgida.
} 
É uníssono que a solução consensual é sempre mais recomendada que o prolongamento do conflito. São inúmeras as vantagens da autocomposição: abrevia o tempo do processo, alcança a paz social de forma construtiva ${ }^{19}$ e dialética, pereniza a harmonia, reduz os custos, etc.

Habituados com uma cultura jurídica de acordos, Kevin Browne e John O’Hare discorrem sobre os seus benefícios para as partes:

Successful negotiations are more desirable than successful litigation. A reasonable compromise saves the client the expense and worry of a trial yet he has still won. The psychological pressure of litigation on a client must never be underestimated. If the case proceeds to trial usually one party wins which necessarily means that the other loses. How much better if both win! ${ }^{20}$.

Neil Andrews, por sua vez, demonstra a importância da transação para a saúde do sistema judiciário:

In general, settlement is better than judgment. Furthermore, if the high level of settlement of civil disputes were to fall even by one or two per cent, the English civil courts would need to try many more cases. This would place the whole system under great pressure, would increase delay in the resolution of cases, and render the civil process more expensive for some litigants ${ }^{21}$.

Não restam dúvidas da essencialidade do papel que a autocomposição passou a exercer no sistema de resolução de conflitos. A sua crescente importância é proporcional às vantagens que ela proporciona às partes e ao sistema judiciário como um todo. Recusar de antemão a sua utilidade nos processos judicias personificados pela Fazenda Pública consiste

${ }^{19}$ DEUTSCH, Morton. The Resolution of Conflict: Constructive and Destructive Processes. New Haven: Yale University Press, 1973. p. 360.

${ }^{20}$ O'HARE, John; BROWNE, Kevin. Civil Litigation. 14.ed. London: Thomson Reuters, 2009. p. 88. Tradução livre: Negociações bem-sucedidas são mais desejáveis do que o litígio bem-sucedido. Um compromisso razoável previne o cliente da preocupação e das despesas de um julgamento, ainda que ele se consagre vencedor. A pressão psicológica de litígio nunca deve ser subestimada. Se o caso for a julgamento, geralmente uma parte vence, o que necessariamente significa que a outra perde. Muito melhor se ambos vencerem!

${ }^{21}$ ANDREWS, Neil. English Civil Procedure: fundamentals of the New Civil Justice System. New York: Oxford University Press, 2003. p. 539. Tradução livre: Em geral, o acordo é melhor que o julgamento. Ademais, se a quantidade de acordos no âmbito de disputas civis diminuísse em um ou dois por cento, os tribunais ingleses precisariam julgar muito mais casos. Isso colocaria todo o sistema sob grande pressão, aumentaria o tempo da resolução dos casos e tornaria o processo mais caro para os litigantes. 
Rio de Janeiro. Ano 11. Volume 18. Número 3. Setembro a Dezembro de 2017

Periódico Quadrimestral da Pós-Graduação Stricto Sensu em Direito Processual da UERJ

Patrono: José Carlos Barbosa Moreira. ISSN 1982-7636. pp. 122-145

www.redp.uerj.br

em grande equívoco, implicando verdadeiro desperdício dos benefícios que as soluções consensuais podem significar para o interesse público. A seguir, procura-se justificar e sistematizar as possibilidades do emprego dessa alternativa, no processo, por parte da Administração Pública.

\section{Relações de direito privado e de direito público}

A viabilidade de solução consensual pela Fazenda Pública passa necessariamente pela análise da natureza do vínculo que esta mantém com o particular interessado, se de direito privado ou se de direito público. Trata-se de categorias de fundamental importância para a sistematização do objeto em estudo.

Não há consenso, porém, a respeito dos limites que separam as relações de direito privado das relações de direito público. Existem múltiplas teorias que se debruçam sobre o tema.

A teoria subjetiva se baseia na qualificação das partes que integram a relação. Considerar-se-ia como de direito público qualquer vínculo de que o Estado faça parte. A caracterização do direito privado se daria de forma residual ${ }^{22}$. Como se verifica abaixo, a corrente carece de respaldo no direito, uma vez que são notáveis os casos em que a Administração compõe relações de direito privado.

No outro polo, a teoria objetiva se ocupa dos interesses perseguidos pelas normas que respaldam o caso concreto. Normas de direito público serviriam aos interesses públicos, ao passo que normas de direito privado serviriam aos interesses individuais ${ }^{23}$. Diz-se que essa teoria não permite uma distinção precisa porque muitas normas levam em consideração interesses públicos e privados ${ }^{24}$.

A teoria da subordinação alude à natureza do vínculo que une as partes. $\mathrm{O}$ direito público se caracterizaria por uma relação de subordinação, enquanto que o direito privado, por uma relação de igualdade. Parte da doutrina rechaça o argumento de que, tanto no direito privado quanto no direito público, existem respectivamente relações de subordinação e de igualdade, a exemplo do que ocorre com os contratos administrativos ${ }^{25}$.

\footnotetext{
${ }^{22}$ CASSAGNE, Juan Carlos. Derecho Administrativo. v. 1, 8.ed. Buenos Aires: LexisNexis, 2006. p. 52.

${ }^{23}$ Ibid., p. 51. MAURER, Harmut. Derecho administrativo alemán. Tradução de José Bobes Sánchez et al. México: Universidad Nacional Autónoma de México, 2012. p. 50.

${ }^{24}$ MAURER, Harmut. Derecho administrativo alemán. Tradução de José Bobes Sánchez et al. México: Universidad Nacional Autónoma de México, 2012. p. 50.

${ }^{25}$ Ibid., p. 51.
} 
Este ensaio, porém, adota como premissa a classificação idealizada por Harmut Maurer. Segundo ele, identifica-se a natureza do vínculo de acordo com a norma aplicada ao caso, sendo certo que pertencem ao direito público aquelas normas que só podem ser atribuídas ao Estado ou a outro sujeito revestido de autoridade. Por outro lado, integram o direito privado as normas que têm como destinatário qualquer sujeito. Nas suas palavras: "El derecho público es así el derecho exorbitante del Estado, y, el derecho privado, el derecho de todos los individuos (incluyéndose entre tales 'individuos' también al Estado), ${ }^{26}$.

Para essa teoria, a dificuldade quase nunca reside na qualificação da norma aplicável, mas sim na identificação da norma que deve reger o caso concreto. É um problema, essencialmente, de atribuição ${ }^{27}$.

Nesse contexto, nada impede que a Administração Pública se submeta também às normas de direito privado. Maurer divide em três grupos os casos em que isso acontece: atividade administrativa de provisão, atividade empresarial da Administração e prestação de serviços públicos sob a forma do direito privado ${ }^{28}$.

O primeiro caso se refere à obtenção de bens e serviços pelo Estado como meio de satisfazer suas funções precípuas. Para tanto, recorre ao mercado, celebrando acordos com empresas privadas sob o manto do direito civil. Na espécie, a Administração atua como se particular fosse.

Em seguida, trata da hipótese de o Estado figurar como empresário, seja através da sua própria atividade empresarial, seja através das empresas estatais. A propósito, no Brasil, por força do art. 173, $\S 1^{\circ}$, II, da Constituição Federal, as ações econômicas da Administração devem necessariamente se sujeitar às normas de direito privado, sendo ilegítimo o exercício de autoridade em relações que se estabelecem nessas circunstâncias.

Por fim, aponta que funções administrativas precípuas também podem ser cumpridas sob a forma do direito privado. Dessas se excluem as atividades indelevelmente ligadas ao emprego de meios de coação, como a tributária ou a de polícia, não podendo a Administração renunciar às prerrogativas próprias do direito público. Nas atividades administrativas de prestação, por outro lado, Maurer entende que o Estado poderá escolher

\footnotetext{
${ }^{26}$ Ibid., p. 51. Tradução livre: O direito público é o direito exorbitante do Estado e o direito privado, o direito de todos os indivíduos (incluindo-se entre tais 'indivíduos' o Estado).

${ }^{27}$ Ibid., p. 53.

${ }^{28}$ Ibid., p. 41-48.
} 
entre oferecer seus serviços valendo-se das formas jurídicas do direito público ou socorrendo-se das de direito privado. Ele acrescenta que a liberdade de opção alcança tanto a forma de organização do serviço quanto a configuração da relação de prestação/utilização ${ }^{29}$. Dessa forma, por exemplo, um Estado-membro poderia optar entre prestar serviço de gás mediante seus próprios meios ou encarregar uma empresa privada do dito serviço. As relações surgidas entre o concessionário e os usuários só podem ser de direito privado. Se, ao contrário, o ente decide prestar por si mesmo o fornecimento de gás, poderá atribuir à relação entre ele e os usuários uma natureza pública ou privada, a depender do que dispor lei de regência.

Por ocasião do julgamento da ADI 447-DF, relatado pelo Ministro Octavio Gallotti, o Ministro Carlos Velloso, em seu voto, se pronunciou sobre os limites da opção de regime por parte do Estado no que toca aos serviços públicos, valendo-se da seguinte classificação:

1) Serviços públicos propriamente estatais, em cuja prestação o Estado atue no exercício de sua soberania, visualizada sob o ponto de vista interno e externo, esses serviços são indelegáveis, porque somente o Estado pode prestá-los. São remunerados, por isso mesmo, mediante taxa. Exemplos: a emissão de passaportes e o serviço jurisdicional. (...) 2) Serviços públicos essenciais ao interesse público são os serviços prestados no interesse da comunidade. São remunerados mediante taxa. E porque as atividades remuneradas são essenciais ao interesse público, à comunidade ou à coletividade, a taxa incidirá sobre a utilização efetiva ou potencial do serviço. Exemplos: os serviços de coleta de lixo e sepultamento. (...) 3) Serviços públicos não essenciais e que, quando não utilizados, disso não resulta dano ou prejuízo para a comunidade ou para o interesse público. Esses serviços são, em regra, delegáveis, vale dizer, podem ser concedidos e podem ser remunerados mediante preço público. Exemplos: o serviço postal, os serviços telefônicos, telegráficos, de distribuição de energia, de gás etc ${ }^{30}$.

Uma ressalva deve ser feita. Em todos os casos em que o Estado atua na órbita do direito privado, ele ainda assim se sujeita a algumas restrições próprias do direito público. Isso vale especialmente para a vinculação aos direitos fundamentais e aos princípios gerais

\footnotetext{
${ }^{29}$ Ibid., p. 45.

${ }^{30}$ BRASIL. Supremo Tribunal Federal. ADI 447 /DF. Brasília, 05 de junho de 1991. p. 80-81.
} 
do direito público. Trata-se do que se convencionou chamar de direito privado administrativo $^{31}$ : um direito privado impregnado por um conjunto de normas de direito público. Sob essa perspectiva, conclui Maurer que, embora a Administração tenha a sua disposição as formas jurídico-privadas, não possui nem a liberdade nem todas as possibilidades que a autonomia da vontade oferece ${ }^{32}$.

\section{Interesse público}

O interesse público deve ser sempre o norte da atividade administrativa. O conceito de interesse público e o peso que lhe é atribuído no caso de conflito com outros interesses resultam da Constituição e da lei ${ }^{33}$. Dessa forma, os interesses públicos podem coincidir total ou parcialmente com os interesses privados, como também podem contradizê-los, a depender do que dispor a ordem jurídica ${ }^{34}$. Celso Antônio Bandeira de Mello se preocupa em explicar a ligação entre o interesse público e o privado:

Deveras, na medida em que se fica com a noção altanto obscura de que transcende os interesses próprios de cada um, sem se aprofundar a compostura desse interesse tão amplo, acentua-se um falso antagonismo entre o interesse das partes e o interesse do todo, propiciando-se a errônea suposição de que se trata de um interesse a se stante autônomo, desvinculado dos interesses de cada uma das partes que compõe o todo. (...) Embora seja claro que pode haver um interesse público contraposto a um dado interesse individual, sem embargo, a toda evidência, não pode existir um interesse público que se choque com os interesses de cada um dos membros da sociedade. Esta simples e intuitiva percepção basta para exibir a existência de uma relação íntima, indissolúvel, entre o chamado interesse público e os interesses ditos individuais ${ }^{35}$.

A doutrina tradicional ${ }^{36}$, baseada nas lições de Renato Alessi, divide o interesse público em primário e secundário. O primeiro relaciona-se com a satisfação das principais necessidades coletivas através do desempenho das funções precípuas do Estado. $\mathrm{O}$

\footnotetext{
${ }^{31}$ WOLFF, Hans J. et al. Direito Administrativo. Tradução de António F. de Sousa v.1. Lisboa: Fundação Calouste Gulbenkian, 2006. p. 314.

${ }^{32}$ MAURER, Harmut. Derecho administrativo alemán. Tradução de José Bobes Sánchez et al. México: Universidad Nacional Autónoma de México, 2012. p. 46.

${ }^{33}$ Ibid., p. 5.

${ }^{34}$ Ibid., p. 6.

${ }^{35}$ MELLO, Celso Antônio Bandeira de. Curso de Direito Administrativo. 21.ed. rev. São Paulo: Malheiros, 2006. p. 56-57.

${ }^{36}$ Ibid., 2006. p. 62-66; OLIVEIRA, Rafael Carvalho Rezende. Curso de Direito Administrativo. 5.ed. São Paulo: Método, 2017. p. 45.
} 
segundo, por sua feita, alude ao interesse da própria Administração, enquanto sujeito de direito e obrigações, e se aperfeiçoa mediante atividades administrativas instrumentais. Celso Antônio Bandeira de Mello minucia a distinção, ao defender a existência do interesse secundário do Estado:

É que, além de subjetivar estes interesses, o Estado, tal como os demais particulares, é, também ele, uma pessoa jurídica, que, pois, existe e convive no universo jurídico em concorrência com todos os demais sujeitos de direito. Assim, independentemente do fato de ser, por definição, encarregado dos interesses públicos, o Estado pode ter, tanto quanto as demais pessoas, interesses que lhe são particulares, individuais, e que, tal como os interesses delas, concebidas nas suas meras individualidades, se encarnam no Estado enquanto pessoa. Estes últimos não são interesses públicos, mas interesses individuais do Estado, similares, pois (sob prisma extrajurídico), aos interesses de qualquer outro sujeito ${ }^{37}$.

A mesma doutrina sustenta que a indisponibilidade do interesse público está indissociavelmente ligada à espécie de interesse público. Enquanto o interesse público primário seria sempre irrenunciável, pois atinentes a toda à coletividade, o interesse público secundário, atendido o princípio da legalidade, seria passível de disposição, uma vez que se revestiria de natureza meramente patrimonial ${ }^{38}$.

Ainda que este trabalho não haja aderido ao seu posicionamento, faz-se menção à doutrina oposta patrocinada por Ricardo Marcondes Martins, segundo a qual "a pressuposição de interesses públicos disponíveis decorre de um vício metodológico, de um vício de premissa teórica, da equívoca pressuposição de que a Administração pode assumir a posição jurídica de um particular e afastar-se do regime de direito público”, na medida

\footnotetext{
${ }^{37}$ MELLO, Celso Antônio Bandeira de. Curso de Direito Administrativo. 21.ed. rev. São Paulo: Malheiros, 2006. p. 62-63.

${ }^{38}$ MEIRELLES, Hely Lopes. Direito Administrativo Brasileiro. 34. ed. São Paulo: Malheiros, 2008. p. 252; GRAU, Eros Roberto. Arbitragem e contrato administrativo. Revista Trimestral de Direito Público. v. 32, p. 14-20, 2000; MOREIRA NETO, Diogo de Figueiredo. Arbitragem nos contratos administrativos. Revista de Direito Administrativo. n. 209. p. 89. São Paulo, jul.-set. 1997. Propondo uma classificação quanto à disponibilidade do direito público material (indisponibilidade absoluta, indisponibilidade relativa e disponibilidade limitada), ver MEIRELLES, Delton Ricardo Soares ; MIRANDA NETTO, Fernando Gama de . Meios alternativos de Resolução de Conflitos envolvendo a Administração Pública. In: XVIII Encontro Nacional do CONPEDI, 2009, Maringá. Anais do XVIII Encontro Nacional do CONPEDI. Santa Catarina: Fundação Boiteux, 2009. p. 6395-6396.
} 
Rio de Janeiro. Ano 11. Volume 18. Número 3. Setembro a Dezembro de 2017

Periódico Quadrimestral da Pós-Graduação Stricto Sensu em Direito Processual da UERJ

Patrono: José Carlos Barbosa Moreira. ISSN 1982-7636. pp. 122-145

www.redp.uerj.br

em que " o interesse público secundário só é reconhecido pelo Direito quando for coincidente com o interesse público primário"39.

A isso replica-se que "não há uma indisponibilidade absoluta, mas um regime público especial de contratação, pagamentos e controle, tanto que a Administração pode indiscutivelmente celebrar contratos típicos e até mesmo atípicos, regidos pelo direito privado" ${ }^{\text {40 }}$. Outrossim, a Lei 13.129/2015 pôs termo à discussão ao autorizar que a Administração Pública se utilize da arbitragem, aludindo expressamente aos seus direitos patrimoniais disponíveis $\left(\operatorname{art.} 1^{\circ}, \S 1^{\circ}\right.$, Lei 9.307/1996).

Cabe ressaltar que a identificação da categoria do interesse público não pode ser feita aprioristicamente, mas apenas diante das particularidades do caso concreto. É este o entendimento de Marco Antônio Rodrigues:

O interesse público é múltiplo e só poderá ser aferido em concreto, diante da situação ocorrida no mundo dos fatos, quando então, a partir de sua definição, se poderá dizer que ele é indisponível, no sentido de que o Estado deverá envidar todos os seus esforços no sentido de concretizá-10 ${ }^{41}$.

Em um esforço de síntese, repisa-se que este artigo adota a corrente, de acordo com a qual o interesse público primário é indisponível, enquanto o secundário, havendo autorização em lei, é disponível. A afirmação servirá de premissa às próximas conclusões deste ensaio.

\section{Soluções consensuais pela Fazenda Pública no direito privado}

Nas relações de direito privado, a Fazenda Pública se encontra no mesmo nível do particular, agindo sem qualquer manifestação de autoridade. Nesse âmbito, as soluções consensuais são muito mais justificáveis. Nessa linha, Ludo Veny et al.: "The increasingly horizontal nature of the relationship between citizen and administration is therefore one of the main reasons for the rise of administrative mediation" ${ }^{\prime 2}$.

\footnotetext{
${ }^{39}$ MARTINS, Ricardo Marcondes. Arbitragem e administração pública: contribuição para o sepultamento do tema. Revista Trimestral de Direito Público. v. 54, p. 194-209, 2011. p. 200.

${ }^{40}$ SOUZA, Rafael Soares. Arbitragem e Administração Pública: comentários ao Projeto de Lei 406/2013. Revista dos Tribunais Nordeste. v. 3. p. 105-127. São Paulo, jan.-fev. 2014. p. 107.

${ }^{41}$ RODRIGUES, Marco Antônio dos Santos. Arbitragem e Fazenda Pública. Revista Eletrônica de Direito Processual - REDP, Rio de Janeiro, v. XIV, n.1, p. 338-410, 2014. p. 400.

${ }^{42}$ VENY, Ludo et al. Mediation in Belgian Administrative Practice, with Special Focus on Municipal Administrative Sanctions and Urban Planning. Mednarodna revija za javno upravo [International Public Administration Review], Ljubljana, v. XII, n. 2-3, p. 169, February 9, 2015. Tradução livre: A crescente
} 
Rio de Janeiro. Ano 11. Volume 18. Número 3. Setembro a Dezembro de 2017

Periódico Quadrimestral da Pós-Graduação Stricto Sensu em Direito Processual da UERJ

Patrono: José Carlos Barbosa Moreira. ISSN 1982-7636. pp. 122-145

www.redp.uerj.br

Quando participa de relações jurídicas de direito privado, a Administração Pública lida, em princípio, com interesses públicos secundários e, em consequência, disponíveis, porquanto afetos à sua esfera patrimonial.

Por essa razão, atendidos os direitos fundamentais e os princípios gerais da atuação administrativa, por exemplo ao princípio da igualdade (as autoridades devem estar em condições de oferecer a mesma disponibilidade dos seus interesses a todos os que se encontrarem em igual situação fática) e ao da legalidade (supremacia da lei), independentemente de prévia autorização legislativa (princípio da reserva da lei), não poderia haver qualquer óbice à renúncia de tais interesses em uma autocomposição capitaneada por uma autoridade, que atua, na espécie, como se particular fosse. ${ }^{43}$

A exigência de prévia autorização legislativa engessaria a Administração e, sobretudo, desnaturaria por completo as relações de direito privado, cuja característica principal reside no autorregramento das partes. ${ }^{44}$ A propósito, lembre-se, que uma delegação genérica do legislador à Administração (como disposto no art. $1^{\circ}$ da Lei $n^{\circ}$ 9.469/97) não atenderia ao fundamento democrático do princípio da reserva da lei. ${ }^{45}$

Marco Antônio Rodrigues, posicionando-se pela viabilidade de a Fazenda realizar arbitragem, vale-se do mesmo argumento:

Os conflitos relativos às cláusulas econômico-financeiras, bem como outros aspectos puramente negociais da relação subjacente ao contrato administrativo, poderão ser levados a juízo arbitral, sem qualquer violação ao princípio da indisponibilidade do interesse público. Isso porque, a rigor, tais aspectos poderiam até mesmo ser negociados extrajudicialmente entre os contratantes ou cumpridos

natureza horizontal da relação entre cidadãos e a Administração Pública é, por isso, uma das razões principais do aumento da mediação administrativa.

${ }^{43}$ Ver art. 71 I e II do Código Modelo de Processos Administrativos - Judicial e Extrajudicial - para IberoAmérica (conf. nota 10 supra), prevendo a legalidade e a isonomia como limites à autocomposição nos conflitos judiciais em direito administrativo.

44 Por exemplo, no campo do direito privado, seria inimaginável condicionar à reserva da lei a responsabilidade civil do Estado por atos ilícitos: "[...] Os créditos oriundos da responsabilidade civil do Estado devem ser cumpridos sem maiores questionamentos e não podem ser rejeitados em favor da precedência do legislador [...]" (GAIER, Reinhard. Prestações positivas contra o Estado e a cláusula da reserva do possível. In: II SEMINÁRIO INTERNACIONAL BRASIL-ALEMANHA, 2011, Florianópolis.

45 Sobre o pricípio da reserva da lei e o princípio democrático, ver MAURER, Harmut. Derecho administrativo alemán. Tradução de José Bobes Sánchez et al. México: Universidad Nacional Autónoma de México, 2012. p. 115. Não mais atende ao princípio da reserva da lei a delegação genérica a autoridades para procederem ingerências a direitos fundamentais a partir da edição de normas próprias (infralegais) (STERN, Klaus. Das Staatsrecht der Bundesrepublik Deutschland. Band II: Staatsorgane, Staatsfunktionen, Finanzund Haushaltsverfassung, Notstandsverfassung. München: C.H.BECK, 1980. § 37, I, 4). 
espontaneamente pelas partes, o que denota sua disponibilidade e, por conseguinte, sua arbitrabilidade. Afinal, como resume Caio Tácito, 'nem todos os contratos administrativos envolvem, necessariamente, direitos indisponíveis da Administração, ${ }^{46}$.

Igualmente apoiando a existência de direitos disponíveis da Fazenda, Heitor Vitor Mendonça Sica corrobora a transação por parte da Fazenda Pública, embora a subordine à previsão legal:

Parece razoável o entendimento de que os direitos patrimoniais da Fazenda Pública são disponíveis nos limites traçados pelo ordenamento jurídico, baseado na mais simples ideia de princípio da legalidade. Ou seja, é necessária norma jurídica expressa para definir de quais direitos da Fazenda os agentes públicos que a representam podem dispor, e os limites e condições para que assim o façam, sem que com isso se considere ferida a indisponibilidade

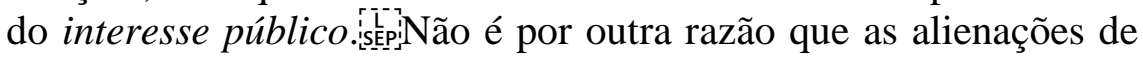
bens públicos são possíveis, mas desde que autorizadas por lei. Da mesma forma, os créditos tributários podem ser excluídos por anistia, exigindo-se apenas que ela seja instituída necessariamente por lei. Finalmente, diversas normas permitem que advogados

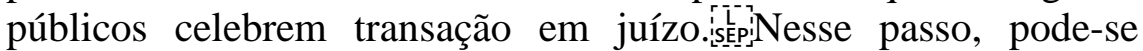
afirmar que a arbitragem sempre foi cabível para solucionar conflitos envolvendo a Fazenda Pública sempre que a lei assim o autorizar $^{47}$.

Como visto acima, a atuação da Administração, ainda que inserida em uma relação de direito privado, não se dá de forma irrestrita. Ela deve sempre respeitar os direitos fundamentais, bem com os demais princípios inerentes à atividade administrativa. Sob essa perspectiva, a solução consensual empreendida pela Fazenda deve atender a esses mesmos limites. É o que pensa Niamh Kinchin, ao pregar o respeito aos valores básicos da democracia, como por exemplo a transparência e a eficiência das transações empreendidas:

All government parties, regardless of their field of expertise, are under an obligation to adhere to the basic values of a democratic government. For mediation to be effective within administrative merits review it is essential that it not be at odds with these values.

\footnotetext{
${ }^{46}$ RODRIGUES, Marco Antônio dos Santos. Arbitragem e Fazenda Pública. Revista Eletrônica de Direito Processual - REDP, Rio de Janeiro, v. XIV, n.1, p. 399-400, 2014.

${ }^{47}$ SICA, Heitor Vitor Mendonça. Arbitragem e Fazenda Pública. [S.1.], 2015. p. 2-3.
} 
[...] The public has the right to know that their taxpayers' dollars are being spent cost-effectively as one of the goals of mediation within a court or tribunal has been cited as cost reduction to the parties, government and the taxpayer ${ }^{48}$.

Do mesmo modo, em seu trabalho sobre a mediação no âmbito da Administração belga, Ludo Veny et al. aponta as balizas que devem ser observadas pela Fazenda Pública em suas transações:

Government may therefore not relinquish its powers and should exercise these in the public interest. [...] Furthermore, the government must always act within the framework of mandatory public law, and will therefore have to take into account the hierarchy of legal norms, the general principles of good governance, and the principle of open government, among other things ${ }^{49}$.

Em suma, quando a Administração assume posição equivalente à de um particular, negociando direitos disponíveis, não há resistência à adoção do emprego da autocomposição no decorrer de um processo judicial. Todavia, não se pode olvidar que o Estado, nessa condição, deve respeitar as balizas e os princípios constitucionais que sempre orientam as suas ações.

\section{Soluções consensuais pela Fazenda Pública no direito público}

As relações de direito público são regidas por normas que colocam a Fazenda Pública em patamar diverso do particular. Nesse contexto, o administrador público representa uma figura dotada de autoridade cuja finalidade perseguida é a concretização do chamado interesse público.

\footnotetext{
${ }^{48}$ KINCHIN, Niamh H. Mediation and Administrative Merits Review: An Impossible Goal? Australasian Dispute Resolution Journal, Riverwood, v.18, n.4, p. 227-233, 2007. p. 230-232. Tradução livre: Todos os âmbitos da Administração Pública, independentemente do seu campo de atuação, estão obrigados a aderir aos valores básicos da democracia. Para que a mediação seja efetiva na avaliação do mérito administrativo, é essencial que não esteja em desacordo com esses valores. [...] O público tem o direito de saber que os dólares dos contribuintes estão sendo gastos de forma eficaz, visto que um dos objetivos da mediação dentro do processo é a redução de custos para as partes, a Administração e o contribuinte.

${ }^{49}$ VENY, Ludo et al. Mediation in Belgian Administrative Practice, with Special Focus on Municipal Administrative Sanctions and Urban Planning. Mednarodna revija za javno upravo [International Public Administration Review], Ljubljana, v. XII, n. 2-3, p. 166, February 9, 2015. Tradução livre: A Administração, portanto, não pode abrir mão dos seus poderes e deve exercê-los em consonância com o interesse público. [...] Além disso, a Administração deve sempre observar as restrições fixadas pelo direito público, levando, assim, em consideração a hierarquia das normas legais, os princípios gerais de boa governança e o princípio da publicidade, entre outras coisas.
} 
O referido interesse público, associado primordialmente ao interesse público primário, se mostra, a princípio, antagônico à possibilidade de transação. Isso se justifica pelo fato de que a interpretação tradicionalmente adotada coloca como sinônimos interesse público e direito indisponível.

Contudo, essa estreita visão pode levar a conclusões errôneas. Não se pode presumir que a Administração Pública está proibida de abdicar de pleito próprio ou de reconhecer pretensões individuais, revendo os seus próprios atos ilegais, independentemente de intervenção judicial. Trata-se de postura decorrente do seu poder administrativo de autotutela ${ }^{50}$ e do dever de cumprir o Direito (princípio da juridicidade ${ }^{51}$ ) e, com isso, atender ao interesse público.

Segue essa mesma lógica o dever de todas as autoridades de adotarem escolhas pautadas no interesse público preponderante no caso concreto, ao ponderarem direitos fundamentais em colisão, como resultado de tomadas de decisões discricionárias. No particular, não raro, a margem de discricionariedade tende a ser reduzida a zero quando diante de direitos fundamentais, razão pela qual, também nessa hipótese, a Fazenda não poderia se furtar de rever, no bojo de eventual processo judicial, os atos por ela praticados, ainda que, a rigor, isso signifique adotar condutas desfavoráveis à sua situação jurídica processual. Repisa-se, não se trata de renúncia ou concessão de "direitos” (poderes), mas sim de cumprimento do dever de sempre se observar o Direito (juridicidade), este sim um comando indisponível, pois essencial à satisfação do interesse público.

\footnotetext{
${ }^{50}$ O poder de autotutela está consagrado em duas súmulas do Supremo Tribunal Federal, a Súmula no 346 : "a Administração Pública pode declarar a nulidade dos seus próprios atos" e a Súmula n 473: "a Administração pode anular os seus próprios atos, quando eivados de vícios que os tornem ilegais, porque deles não se originam direitos; ou revogá-los, por motivo de conveniência ou oportunidade, respeitados os direitos adquiridos, e ressalvada, em todos os casos, a apreciação judicial", e atualmente disposto no art. 53 da Lei 9.784/99.

${ }^{51}$ Maria Sylvia Zanella Di Pietro disserta sobre os efeitos desse princípio: "Com a Constituição de 1988, optou-se pelos princípios próprios do Estado Democrático de Direito. Duas ideias são inerentes a esse tipo de Estado: uma concepção mais ampla do princípio da legalidade e a ideia de participação do cidadão na gestão e no controle da Administração Pública. No que diz respeito ao primeiro aspecto, o Estado Democrático de Direito pretende vincular a lei aos ideais de justiça, ou seja, submeter o Estado não apenas à lei sentido puramente formal, mas ao Direito, abrangendo todos os valores inseridos expressa ou implicitamente. [...] A constitucionalização dos princípios da Administração conferiu ao Poder Judiciário e aos demais órgãos de controle a possibilidade de examinar aspectos do ato antes vedado ao Poder Judiciário". (DI PIETRO, Maria Sylvia Zanella. Direito Administrativo. 28.ed. São Paulo: Editora Atlas S.A., 2015. p. 37-38).
} 
Em síntese, agir conforme o Direito, ainda que para isso seja necessário renunciar ou reconhecer juridicamente a pretensão da parte litigante adversa, encerra dever de todas as autoridades, que devem sempre estar em busca da satisfação do interesse público.

A apuração inspira-se em ensinamentos de Eduardo Talamini:

As constatações a respeito da indisponibilidade do interesse público não afetam outra diretriz fundamental da atuação pública: a Administração, uma vez constatando que não tem razão em dado conflito, tem o dever de submeter-se aos parâmetros da legalidade. Em regra, tal submissão independe da instauração de processo judicial. Trata-se de imposição inerente à própria relação material de direito público: se o Estado constata que o particular tem determinado direito em face dele, cabe-lhe dar cumprimento tal direito. Isso é decorrência direta do princípio constitucional da legalidade (CF, art. 37, caput). Se a todo sujeito de direito a imposição de cumprir seus deveres já se colocaria, aos entes e agentes da Administração Pública ela se põe com ainda maior vigor. Para eles, a legalidade não é apenas um limite, uma baliza, mas vetor fundamental da sua atuação ${ }^{52}$.

Ademais, são cediços os casos em que a lei outorga à Administração verdadeiro poder discricionário, situação na qual o interesse público pode ser realmente atendido de mais de uma maneira possível. Na hipótese, poder-se-ia cogitar de uma transação entre o particular e a Fazenda, que tivesse por objeto aqueles meios possíveis de se alcançar o interesse público. Isso porque, desde que, no fim, o interesse público indisponível seja assegurado, a escolha entre essas opções revela-se disponível, contanto que sejam observados os princípios regentes da atividade administrativa.

Marco Antônio Rodrigues adota o mesmo fundamento para apoiar a participação da Fazenda em procedimentos arbitrais:

A indisponibilidade do interesse público não se confunde com a disponibilidade de meios para atingi-lo, sendo que o mecanismo mais adequado para tanto pode, à luz de uma análise efetuada com base nas circunstâncias concretas, ser a arbitragem, o que revela a

\footnotetext{
52 TALAMINI, Eduardo. A (in)disponibilidade do interesse público: consequências processuais. [S.1.], 2005. p. 3.
} 
impropriedade de se invocar o princípio da indisponibilidade do interesse público como óbice a sua utilização por entes públicos ${ }^{53}$.

O fato é que deveria haver no mínimo uma simetria entre os casos que envolvem poder administrativo discricionário e os casos em que Administração poderia se sujeitar à solução consensual na seara judicial. Do contrário, conclui-se que a Administração, fora do processo, pode mais. Se, por um lado, o poder discricionário é guiado pelo interesse publico, por outro lado, a solução consensual pode ser um instrumento útil a esses mesmos fins, inclusive com maior efetividade, pois geraria coisa julgada.

Evidenciando os claros benefícios das soluções consensuais para a Fazenda Pública, Niamh Kinchin afirma: "Strong arguments also exist for the benefits of mandatory mediation. Better case-management and cost saving are evident but even more importantly, so is the encouragement of the propagation of an ADR culture over the traditional adversarial one" 54 .

Ludo Veny et al. conclui que o recurso à autocomposição pelo Estado pode representar inclusive uma forma eficaz de se alcançar o interesse público:

When applied in administrative law, mediation offers possibilities in examining a dispute beyond the boundaries of a specific administrative action, and in its full complexity. Resolving disputes through mutual agreement and dialogue will result in a more stable relationship between government and citizens in the future, which will have positive spill-over effects in society as a whole. [...] For these reasons, we argue in favor of a global mediation regulation that is applicable to public law as well as to other branches of law ${ }^{55}$.

\footnotetext{
${ }^{53}$ RODRIGUES, Marco Antônio dos Santos. Arbitragem e Fazenda Pública. Revista Eletrônica de Direito Processual - REDP, Rio de Janeiro, v. XIV, n.1, p. 400, 2014.

${ }^{54}$ KINCHIN, Niamh H. Mediation and Administrative Merits Review: An Impossible Goal? Australasian Dispute Resolution Journal, Riverwood, v.18, n.4, p. 233, 2007. Tradução livre: Também existem fortes argumentos em prol da mediação obrigatória. Uma melhor gestão de casos e a economia de custos são benefícios evidentes, porém ainda mais importante é o encorajamento da propagação de uma cultura de ADR em detrimento da tradicional cultura adversarial

${ }^{55}$ VENY, Ludo et al. Mediation in Belgian Administrative Practice, with Special Focus on Municipal Administrative Sanctions and Urban Planning. Mednarodna revija za javno upravo [International Public Administration Review], Ljubljana, v. XII, n. 2-3, p. 177-178, February 9, 2015. Tradução livre: Quando aplicada no direito administrativo, a mediação oferece a possibilidade de se examinar uma disputa além dos limites de uma ação administrativa específica, tratando, ao revés, de toda a sua complexidade. A resolução de disputas por mútuo acordo e diálogo resultará em uma relação mais estável no futuro entre a Administração e
} 
É certo que já não satisfaz uma decisão unilateral da Administração, ínsita à relação de subordinação do direito público. Os meios consensuais se apresentam como uma forma de diluir o poder decisório, exigindo cada vez mais a participação de quem será objeto da sua aplicação ${ }^{56}$. Negar essa alternativa no curso do processo judicial revela enorme contradição no sistema judiciário.

\section{Conclusão}

Conclui-se, assim, que a possibilidade de a Fazenda realizar transação ou praticar condutas determinantes no processo judicial não deve ser aprioristicamente rechaçada. É dizer, nem todas as posições jurídicas defendidas pelo Poder Público em juízo são indisponíveis. Não se pode perder de perspectiva que só é indisponível o interesse público (interesse público primário), não o interesse econômico da Administração (interesse público secundário).

Assentadas essas premissas, vislumbram-se três cenários quanto à possibilidade do emprego de meios consensuais pela Fazenda no processo judicial.

Primeiramente, quando participa de relações de direito privado, independentemente de prévia autorização legislativa, não haveria qualquer obstáculo à autocomposição por parte da Fazenda Pública, pois atinente tão somente ao interesse disponível da Administração.

Em segundo lugar, nas relações de direito público, quando diante de situação ilegal, a prática de condutas processuais determinantes, tais como o reconhecimento da procedência do pedido ou a renúncia, deixa de ser uma faculdade, passando a consistir em verdadeira conduta vinculada da Fazenda, decorrente do seu poder de autotutela e da subordinação ao Direito (juridicidade).

Por fim, nas situações do direito público em que se nota certo grau de discricionariedade da Administração, esta deve se refletir na mesma medida no bojo do processo judicial. Trata-se dos casos em que lhe é conferido verdadeiro poder

os cidadãos, o que produzirá efeitos positivos para toda a sociedade como um todo. [...] Por essas razões, advogamos em favor de uma regulamentação sobre a mediação aplicável ao direito público, bem como a outros ramos do direito. Sobre o cabimento da ADR na "administrative adjudication" do Reino Unido, Estados Unidos e Austrália, ver CANE, Peter. Por que ter tribunais administrativos? Tradução de Juliana Perlingeiro. A\&C-Revista de Direito Administrativo e Constitucional, Belo Horizonte, 2017, prelo.

${ }^{56}$ GORDILLO, Agustín. Tratado de Derecho Administrativo. v. 1, 9.ed. México: Editorial Porrúa, 2004. p. 60 . 
Rio de Janeiro. Ano 11. Volume 18. Número 3. Setembro a Dezembro de 2017 Periódico Quadrimestral da Pós-Graduação Stricto Sensu em Direito Processual da UERJ Patrono: José Carlos Barbosa Moreira. ISSN 1982-7636. pp. 122-145 www.redp.uerj.br

discricionário na busca do interesse público, podendo ela optar entre mais de um meio possível para alcançá-lo. Em tal conjuntura, não há por que negar à Fazenda a possibilidade de buscar uma decisão que atenda ao interesse público a partir do consenso com a parte adversa.

Pensar de modo contrário significaria afirmar que a Administração pode menos no processo judicial do que fora dele.

\section{REFERÊNCIAS BIBLIOGRÁFICAS:}

ANDREWS, Neil. English Civil Procedure: fundamentals of the New Civil Justice System. New York: Oxford University Press, 2003.

CANE, Peter. Por que ter tribunais administrativos? Tradução de Juliana Perlingeiro. $A \& C$ - Revista de Direito Administrativo e Constitucional, Belo Horizonte, 2017, prelo.

CASSAGNE, Juan Carlos. Derecho Administrativo. v.1, 8. ed. Buenos Aires: LexisNexis, 2006.

DEUTSCH, Morton. The Resolution of Conflict: Constructive and Destructive Processes. New Haven: Yale University Press, 1973.

DIDIER JÚNIOR, Fredie. Curso de Direito Processual Civil. v.1, 17. ed. rev. atual. e ampl. Salvador: Editora Jus Podium, 2015.

DI PIETRO, Maria Sylvia Zanella. Direito Administrativo. 28. ed. São Paulo: Editora Atlas S.A., 2015.

GAIER, Reinhard. Prestações positivas contra o Estado e a cláusula da reserva do possivel. In: II SEMINÁRIO INTERNACIONAL BRASIL-ALEMANHA, 2011, Florianópolis. Disponível em: < http://bit.ly/2uIDaoB >. Acesso em: 18 jul. 2017. Organizado pelo Centro de Estudos Judiciários (CEJ) do Conselho da Justiça Federal (CJF). Versão impressa: II Seminário Internacional Brasil-Alemanha: Thompson Flores (português-alemão): 16 e 17 de junho de 2011, Florianópolis, Brasil/Conselho da Justiça Federal, Centro de Estudos Judiciários; coordenação científica Márcio Flávio Mafra Leal - Brasília: CJF, 2011. - (Série Cadernos CEJ: 27).

GELLHORN, Ernest; LEVIN, Ronald M. Administrative Law and Process in a Nutshell. 5. ed. St. Paul: Thomson/West, 2006. 
Rio de Janeiro. Ano 11. Volume 18. Número 3. Setembro a Dezembro de 2017

Periódico Quadrimestral da Pós-Graduação Stricto Sensu em Direito Processual da UERJ

Patrono: José Carlos Barbosa Moreira. ISSN 1982-7636. pp. 122-145

GORDILLO, Agustín. Tratado de Derecho Administrativo. v.1, 9. ed. México: Editorial Porrúa, 2004.

GRAU, Eros Roberto. Arbitragem e contrato administrativo. Revista Trimestral de Direito Público. n. 32, p. 14-20, 2000.

GRINOVER, Ada Pellegrini; PERLINGEIRO, Ricardo; BARRANTES, Sergio Artavia; PALACIO, Ruth Stella Correa; CUEVAS, Euripides; FERREIRA DA SILVA, Carlos Manuel; Morelos, Gumesindo García; GUTIÉRREZ Sanz, Maria Rosa García; Sosa, Angel Landoni; Medauar, Odete; Garzón, Juan Antonio Robles; SIMONS, Adriáns; Bracesco, Ignacio M. Soba; ZAMORANO, Abel Augusto. Código Modelo de Processos Administrativos - Judicial e Extrajudicial - para IberoAmérica (Model Code of Judicial and Extrajudicial Administrative Procedures for Ibero-America). Revista Eletrônica de Direito Processual, Rio de Janeiro, v.X, p. 360-383, 2012. Disponível em: 〈https://ssrn.com/abstract=2250818>. Acesso em: 4 jul. 2017.

KINCHIN, Niamh H. Mediation and Administrative Merits Review: An Impossible Goal? Australasian Dispute Resolution Journal, Riverwood, v.18, n.4, p. 227-233, 2007. Disponível em: < http://bit.ly/2f4PSlf > . Acesso em: 17 nov. 2016.

MARINONI, Luiz Guilherme; ARENHART, Sérgio Cruz; MITIDIERO, Daniel. Curso de Processo Civil: Teoria do Processo Civil. v. 1. São Paulo: Editora Revista dos Tribunais, 2015.

MARTINS, Ricardo Marcondes. Arbitragem e administração pública: contribuição para o sepultamento do tema. Revista Trimestral de Direito Público. v. 54, p. 194-209, 2011.

MAURER, Harmut. Derecho administrativo alemán. Tradução de José Bobes Sánchez et al. México: Universidad Nacional Autónoma de México, 2012.

MEIRELLES, Delton Ricardo Soares; MIRANDA NETTO, Fernando Gama de. Meios alternativos de Resolução de Conflitos envolvendo a Administração Pública. In: XVIII Encontro Nacional do CONPEDI, 2009, Maringá. Anais do XVIII Encontro Nacional do CONPEDI. Santa Catarina: Fundação Boiteux, 2009. p. 6385-6417.

MEIRELLES, Hely Lopes. Direito Administrativo Brasileiro. 34. ed. São Paulo: Malheiros, 2008. 
Rio de Janeiro. Ano 11. Volume 18. Número 3. Setembro a Dezembro de 2017

Periódico Quadrimestral da Pós-Graduação Stricto Sensu em Direito Processual da UERJ Patrono: José Carlos Barbosa Moreira. ISSN 1982-7636. pp. 122-145

MELlO, Celso Antônio Bandeira de. Curso de Direito Administrativo. 21. ed. rev. São Paulo: Malheiros, 2006.

MOREIRA NETO, Diogo de Figueiredo. Arbitragem nos contratos administrativos. Revista de Direito Administrativo. n. 209. p. 89. São Paulo, jul.-set. 1997.

O'HARE, John; BROWNE, Kevin. Civil Litigation. 14.ed. London: Thomson Reuters, 2009.

OLIVEIRA, Rafael Carvalho Rezende. Curso de Direito Administrativo. 5. ed. São Paulo: Método, 2017.

PERLINGEIRO, Ricardo. Desafios contemporâneos da justiça administrativa na América Latina. Revista de Investigações Constitucionais, Curitiba, v. 4, n. 1, p. 167-205, jan./abr. 2017.

PERLINGEIRO, Ricardo; SOMMERMANN, Karl-Peter. Euro-American Model Code of Administrative Jurisdiction: English, French, German, Italian, Portuguese and Spanish Versions. Niterói: Editora da UFF, 2014.

PERLINGEIRO, Ricardo (Org.). Procedimento Administrativo e Processo Administrativo Latino-Americanos: Compilação de Leis Nacionais. Rio de Janeiro: Escola da Magistratura Regional Federal - EMARF, 2017.

PICARDI, Nicola. Manuale del Processo Civile. 2. ed. Milano: Giuffrè Editore, 2010.

RODRIGUES, Marco Antônio dos Santos. Arbitragem e Fazenda Pública. Revista Eletrônica de Direito Processual - REDP, Rio de Janeiro, v. XIV, n.1, p. 338-410, 2014. Disponível em: 〈http://bit.ly/2g2if47> . Acesso em: 17 nov. 2016.

SICA, Heitor Vitor Mendonça. Arbitragem e Fazenda Pública. [S.1.], 2015. Disponível em: <http://bit.ly/2fLZNOe> . Acesso em: 17 nov. 2016.

SOUZA, Rafael Soares. Arbitragem e Administração Pública: comentários ao Projeto de Lei 406/2013. Revista dos Tribunais Nordeste. vol. 3. p. 105-127. São Paulo, jan.fev. 2014.

STERN, Klaus. Das Staatsrecht der Bundesrepublik Deutschland. Band II: Staatsorgane, Staatsfunktionen, Finanz- und Haushaltsverfassung, Notstandsverfassung. München: C.H.BECK, 1980. 
Revista Eletrônica de Direito Processual - REDP.

Rio de Janeiro. Ano 11. Volume 18. Número 3. Setembro a Dezembro de 2017

Periódico Quadrimestral da Pós-Graduação Stricto Sensu em Direito Processual da UERJ

Patrono: José Carlos Barbosa Moreira. ISSN 1982-7636. pp. 122-145 www.redp.uerj.br

TALAMINI, Eduardo. A (in)disponibilidade do interesse público: consequências processuais. [S.1.], 2005. Disponível em: 〈http://bit.ly/2fbqY6H> . Acesso em: 17 nov. 2016.

VENY, Ludo; CARLENS, Ivo; VERBEECK, Bengt \& WARNEZ, Brecht. Mediation in Belgian Administrative Practice, with Special Focus on Municipal Administrative Sanctions and Urban Planning. Mednarodna revija za javno upravo [International Public Administration Review], Ljubljana, v. XII, n. 2-3, p. 163-181, February 9, 2015. Disponível em: < https://ssrn.com/abstract=2562297>. Acesso em: 17 nov. 2016.

WOLFF, Hans J.; BACHOF, Otto; STOBER, Rolf. Direito Administrativo. Tradução de António F. de Sousa. v.1. Lisboa: Fundação Calouste Gulbenkian, 2006. 